\title{
Capsule Commentary on Schapira et al., Inadequate Systems to Support Breast and Cervical Cancer Screening in Primary Care Practice
}

\author{
Ilana Beth Richman, MD
}

Palo Alto VA Health Care System/Stanford University School of Medicine, Palo Alto, CA, USA.

J Gen Intern Med 31(10): 1215

DOI: $10.1007 / \mathrm{s} 11606-016-3748-5$

() Society of General Internal Medicine 2016

A bout $30 \%$ of women aged 50-64 years have not had a recent mammogram and $20 \%$ of women 21-65 are not up to date on cervical cancer screening. ${ }^{1}$ Targeted interventions like patient letters, electronic health record (EHR) reminders, and comparative performance reports can help to narrow this gap. ${ }^{2,3}$ We have tools that work. So are we doing all we can to ensure patients receive recommended preventives services?

In this issue of JGIM, Schapira and colleagues quantify the use of systems to support cancer screening in primary care and examine the correlates of these systems on both the provider and practice level. ${ }^{4}$ Their findings provide insights that may help focus future implementation efforts. The authors report that about half of practices use EHR reminders, the most common systems-level intervention. Many fewer use more complex strategies like identifying patients who have missed screenings or offering providers' feedback on their practice patterns.

Who uses these systems? Practices that are part of a patientcentered medical home (PCMH) are more likely to use certain systems-level interventions such as comparative performance reports or automated reports of patients overdue for screening. This finding is not surprising, given both the goals and requirements for the PCMH model. It is reassuring, though, that PCMH practices are indeed doing things differently. Perhaps more intriguingly, provider - level characteristics were strongly associated with some systems-level interventions. In particular, obstetricians were less likely to have access to some systems-level supports and non-physician providers were less likely to receive comparative performance reports.
These findings have direct implications for health policy and health care delivery improvement efforts. Above all, these findings suggest that we have more work to do in incorporating evidence-based tools and systems that can facilitate cancer screening. PCMH practices may lead the way and likely have valuable lessons to share about how to implement these interventions. In addition, we should ensure that all primary care providers have adequate systems in place to facilitate screening, regardless of specialty or discipline. Building specific systems to engage patients and providers in cancer screening will allow us to offer screening to all who may benefit.

Corresponding Author: Ilana Beth Richman, MD; Palo Alto VA Health Care System/Stanford University School of Medicine, Palo Alto, CA, USA (e-mail: irichman@stanford.edu).

\section{Compliance with Ethical Standards:}

Conflict of Interest: The author has no conflict of interest with this article.

\section{REFERENCES}

1. Cancer Prevention \& Early Detection Facts \& Figures 2015-Acspc045101.pdf.; 2015. http://www.cancer.org/acs/groups/content/@research/documents/webcontent/acspc-045101.pdf. Accessed May 4, 2016.

2. Baron RC, Melillo S, Rimer BK, et al. Intervention to increase recommendation and delivery of screening for breast, cervical, and colorectal cancers by healthcare providers a systematic review of provider reminders. Am J Prev Med. 2010;38(1):110-117. doi:10.1016/j.amepre.2009.09.031.

3. Sabatino SA, Lawrence B, Elder R, et al. Effectiveness of interventions to increase screening for breast, cervical, and colorectal cancers: nine updated systematic reviews for the guide to community preventive services. Am $J$ Prev Med. 2012;43(1):97-118. doi:10.1016/j.amepre.2012.04.009.

4. Schapira MM, Sprague BL, Klabunde CN, Tosteson ANA, Bitton A, Chen JS, Beaber EF, Onega T, MaclLean CD, Harris K, Howe K, Pearson L, Feldman S, Brawarsky P, Haas JS. Inadequate systems to support breast and cervical cancer screening in primary care practice. J Gen Intern Med. doi:10.1007/s11606-016-3726-y. 